\title{
Domestic Violence and Women's Employment: Fixed Effects Models of Three Waves of Women's Employment Study Data
}

\author{
Richard M. Tolman ${ }^{1,3}$ and Hui-Chen Wang ${ }^{2}$
}

\begin{abstract}
Domestic violence can interfere with women's ability to work, and may result in loss of welfare benefits and poorer economic outcomes. Previous studies showing no effect of domestic violence on employment could be a result of the failure to control for some individual characteristics; therefore we use fixed-effects models with three waves of Women's Employment Study (WES) data to control for unobservable time-invariant individual-specific characteristics. Included in our analyses were 598 women, from an urban county in Michigan who were on the welfare rolls in February of 1997, all of whom completed 3 waves of interviews. Our fixed effects regression results show that domestic violence significantly reduced the annual work hours of a respondent. Mental and physical health problems do not completely mediate this relationship. Our results support efforts to address domestic violence within the welfare system.
\end{abstract}

KEY WORDS: domestic violence; employment; welfare; abuse.

Domestic violence may impact many spheres of a woman's life and examining whether an association exists between domestic violence and work outcomes is important for several reasons. First, rates of abuse are higher among women receiving welfare than among nonrecipients (Tolman \& Raphael, 2000). Secondly, battered women may depend on the welfare system to provide economic support to leave an abusive partner. For example, Goodwin, Meisel, Chandler, Jordan, and Cushner (2000) reported that one fifth of women on welfare caseloads in four California counties had at one time used welfare to escape an abusive situation. Finally, because of changes in the welfare laws, subsequent to the passage of the 1996 Personal Responsibility Work Opportunity Reconcilation Act (PRWORA), women who fail to work or participate in mandatory

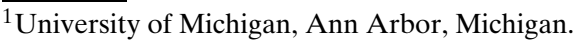

${ }^{2}$ University of Mississippi, University, Missouri.

${ }^{3}$ To whom correspondence should be addressed at University of Michigan, School of Social Work, 1080 S. University Avenue, Ann Arbor, Michigan 48109-1106; e-mail: rtolman@umich.edu.
}

training programs are more likely to be sanctioned by loss of welfare benefits. PRWORA ended federal entitlement to welfare benefits, set limits on the number of years women could receive welfare, and required rapid entry into the work force to maintain welfare benefits. Responding to the concern that women experiencing domestic violence will be unable to fulfill these work requirements, most states have adopted the Family Violence Option, which allows temporary exemptions or deferments to work requirements and makes provisions for services to aid recipients dealing with abuse (Raphael \& Haennicke, 1999).

One key rationale behind the policies provided by the Family Violence Option is that women's intimate partners use coercion to sabotage participation in work or educational programs (Raphael \& Haennicke, 1998). Abusive partners may block women's attempts to go to work, in part, because economic self-sufficiency may challenge abusers' control. Early studies, conducted by Raphael (1995, 1996) demonstrated that many women face abuse by their partners that interferes with their attempts to go to work or participate in training. 
Subsequent studies provided further evidence that such direct interference does indeed occur (Allard, Albelda, Colten, \& Cosenza, 1997; Barusch, Taylor, Abu-Bader, \& Derr, 1999; Pearson, Thoennes, \& Griswold, 1999; Tolman \& Rosen, 2001). This interference may take many forms, such as keeping a partner from sleeping, destroying work clothes or job applications, threatening or using force to impede her leaving for work or job interviews (Raphael, 1996).

In addition to direct work interference, the adverse health and mental health outcomes that can result from violence may create disadvantage in the workplace for battered women. The negative health and mental health impacts of domestic violence have been well documented (Campbell \& Lewandowski, 1997; Coker et al., 2002; Porcerelli et al., 2003; Sutherland, Bybee, \& Sullivan, 2002). Domestic violence has been linked to multiple health problems, and numerous chronic conditions including gastrointestinal, gynecological, and cardiac health problems (Campbell, 2002; Campbell \& Lewandowski, 1997). For example, in a recent large sample HMO case control study, Campbell et al. (2002) found that abused women, when compared to those who were never abused, had higher levels of gynecological, chronic stress-related, central nervous system, and total health problems and more of the following symptoms: abdominal, pelvic, and back pain, appetite loss, urinary tract infections, vaginal bleeding and infections, painful intercourse, and digestive problems.

Domestic violence has also been linked to increased rates of mental health problems including depression and suicidal ideation, posttraumatic stress disorder, and alcohol and drug abuse (Cascardi et al., 1999; Coker et al., 2002; Sutherland et al., 2002). In a meta-analysis, Golding (1999) found high rates of depression, suicidality, posttraumatic stress disorder, and drug abuse among those experiencing partner violence. Generally, the research results were consistent in demonstrating increased risk for mental health problems in those experiencing intimate partner violence.

In exploring the relationship among domestic violence, health and income, Sutherland, Sullivan, and Bybee (2001) found that abuse predicted variance in health outcomes beyond the effects of income alone. In the specific context of women and welfare, Lloyd (1997) found that women who experienced domestic violence in their adult relationships were more likely to suffer from physical and mental health problems. Browne, Salomon, and Bassuk (1999) studied abused and nonabused poor women, most of whom were re- ceiving welfare benefits. Those who were assaulted by intimate partners during the previous year reported significantly higher rates of mental health and physical health problems, more hospitalizations, and more substance abuse problems than did their nonabused counterparts. Further, women with mental health disorders in their sample had only half the odds of maintaining work as women without mental health disorders. Tolman and Rosen (2001), using first-wave data from the Womens' Employment Study (WES), found that $62 \%$ of recent victims of severe violence had at least one of five disorders measured, compared to $34 \%$ of past victims, and $23 \%$ of those who had never experienced severe abuse. Both recent and past victims of domestic violence victims also had higher levels of physical health problems than those who had never experienced domestic violence.

\section{Theoretical Perspectives}

Perhaps the most influential perspective applied to domestic violence research is feminist theory (Gelles, 1993). According to feminist theory, male violence against women in intimate relationships is one tool that serves to support societal male dominance in society. On the structural level, by creating fear or physical or psychological debilitation, men's violence can restrict and subordinate women's participation in societal institutions. On the relationship level, men use violence in their intimate relationships as a means of gaining power over and controlling their partners (Bograd, 1988; Yllo, 1993). From this perspective, men's sabotage of their female partner's employment would be understood to be motivated by a desire to maintain male dominance in the economic sphere, and to restrict women to subordinate roles within the family (Raphael, 2000; Riger \& Krieglestein, 2000). Women's employment may be threatening to men because it may provide women with economic autonomy from their male partners. By restricting women's economic autonomy, men would increase the probability that their partners would remain dependent upon them, and increase their ability to control their partners' behavior within the relationship. Feminist theory therefore provides an explanation for the direct impact of domestic violence on employment: men are motivated to block their partners attempt to obtain and maintain employment outside the home and violence is used, among other tactics, to purposely sabotage their partners efforts at work. 
Not all violence however may be undertaken for the specific purpose of blocking employment. Feminist theory also accounts for the use of violence in service of control of other behaviors. For example, men may use violence to punish and suppress women's speech that challenges an abuser, or to reinforce demands for material, emotional, or sexual services (Dobash \& Dobash, 1979). In this context, domestic violence may impact employment even if it is not explicitly motivated by attempts to dissuade women from entering or remaining in the labor market. Rather, the deleterious effects of violence on women's physical, psychological, and emotional wellbeing, whatever the specific motivation, could impede employment success.

\section{Research on Domestic Violence and Employment}

Whether the causal route is through direct interference by abusers, or through the adverse effects of the violence on women's ability to work, without work or welfare benefits, women may face extreme economic deprivation as a result of the domestic violence in their lives. Despite these concerns, the link between domestic violence and employment has not been strongly demonstrated in previous research. Several cross-sectional studies failed to provide evidence that domestic violence resulted in poorer work outcomes for women on welfare (Barusch et al., 1999; Lloyd, 1997; Tolman \& Rosen, 2001). Lloyd and Taluc (1999) found that women who experienced male violence were no less likely to be currently employed than were women who had not, though they were more likely to have experienced unemployment in the past and higher job turnover rates. Two longitudinal studies however, do provide some evidence that domestic violence is related to negative work outcomes for women. For example, Brown et al. (1999) examined the work experiences of homeless and housed women in a small city in Massachusetts, most of whom were welfare recipients. Women who experienced physical aggression by their partner during the first year follow-up period had one third the odds of working at least $30 \mathrm{hr}$ per week for at least 6 months than did those who did not experience intimate aggression. Additionally, in a study of data from welfare programs in Wisconsin, Moore and Selkowe (1999) found that controlling for age and education, current victims of abuse are $15 \%$ less likely to be employed than are past victims.
Given these mixed results, it is important to further examine the role of domestic violence in predicting work outcomes. In this study, we attend to a number of methodological issues that may have limited previous studies. Particularly, we address issues that may lead to a failure to detect an effect of domestic violence on employment. We use longitudinal data from the first three waves of Women's Employment Study (WES) data to investigate the effects of domestic violence on women's employment outcomes. We argue that the insignificant estimates of the effects in some studies could be biased as a result of the failure to control for some individual characteristics. Therefore, instead of the more frequently used basic OLS or logistic regressions, we apply fixed-effects models, which provide the ability to control for time-invariant individual-specific characteristics that are unobservable to the researchers. Failure to control for such characteristics would lead to inconsistent estimators if the unobservables are correlated with the observed variables that are included in the analysis. In addition, we specify a dependent variable that may be more sensitive to the impact of domestic violence on employment. Rather than measure whether a woman is employed or not at a certain level (e.g. more than 20 or $30 \mathrm{hr}$ per week), we estimate the total annual work hours of women in our sample. This continuous measure of employment takes into account both the intensity and the persistence of a woman's work participation. Finally, because the impact on employment may be mediated by the adverse effects of domestic violence on health and mental health, insignificant coefficients of domestic violence obtained from models including these health variables may be misinterpreted as demonstrating no effect of domestic violence on employment. Even if domestic violence does not have direct impact on women's work, the violence could lead to mental and/or physical health conditions that reduce women's work indirectly. Therefore, a lack of a direct impact should not be viewed as a dismissal of domestic violence's role in explaining women's work behavior. To address this, we compare the effect of domestic violence when health and mental health variables are included and excluded from models.

We hypothesize that domestic violence does impact women's annual work hours. We hypothesize that the effects of domestic violence will be partially mediated by health and mental health conditions that could result from the abuse, but there will remain a direct effect of the violence as well. A significant effect for domestic violence when controlling 
for measured and unmeasured characteristics of the women would be consistent with feminist theory which posits that abuse by men of their partners is motivated by a desire to limit women's employment and is not explained by individual or psychological characteristics of the women themselves.

\section{METHODS}

\section{Participants}

We use data from the first three waves of Women's Employment Study, a longitudinal study of a sample of women who were on the welfare rolls in February 1997 . The sample was systematically drawn with equal probability from an ordered list of single mothers in an urban Michigan county who received cash assistance from Temporary Assistance to Needy Families (TANF) in February 1997. The sample was limited to U.S. citizens who were either White or African American between age 18 and 54. The first three waves of interviews were conducted in Fall 1997, Fall 1998, and Fall 1999, respectively. The response rate was $86 \%$ for the first wave $(N=$ $753)$. In the second wave, $92 \%$ of the first wave respondents were interviewed, and $91 \%$ of the second wave respondents were interviewed in the third wave $(N=632)$. Women who received SSI benefits at any of the three waves $(N=27)$ were excluded from the analysis because they would not be expected to seek employment. Women were included in the sample whether or not they were currently in romantic relationships. Because they may experience violence by former partners, such as the fathers of their children, even if separated or in a subsequent relationship, we did not limit our analyses to cohabiting or romantic couples only.

Our analysis uses only respondents who appear at least twice due to the use of fixed effects models. Consequently, our stacked analysis sample has 1768 observations, which are composed of repeated observations of 598 respondents who have valid values for all of our controlled variables in at least two periods out of three.

\section{Measures}

\section{Annual Work Activities}

We impute the number of hours that a respondent worked on all jobs in each calendar year. This continuous measure of work takes into account both the intensity and the persistence of a woman's work participation. At each wave of WES, women were asked how many hours per week they worked on all jobs if they were then currently working for pay. For those who were not currently employed, WES collected information about the weekly hours worked on the most recent job. WES also collected information on respondents' work status in each month starting February 1997 through the month of the latest interview. Using this information we compute the percent of months worked in calendar year 1997, 1998, and 1999. This percentage is then multiplied by 52 to impute the number of weeks worked in the calendar year. ${ }^{4}$ The annual work hours measure is defined as the self-reported weekly hours worked on all then-current jobs or the most recent job multiplied by the imputed annual weeks worked.

\section{Domestic Violence}

Domestic violence was assessed with a modified version of the Conflict Tactics Scale (Straus, 1979). For this study we use a six-item severe violence measure (hit you with a fist, hit you with an object that could hurt you, beaten you, choked you, threatened to or used a weapon, forced you into any sexual activity against your will). At Wave 1, women were asked if they had ever experienced these forms of abuse in their relationships, and if they had experienced them in the past 12 months (Wave 112-month $\alpha=.81$, lifetime $\alpha=.86$ ). At Wave 2 and Wave 3, they were again asked if they had experienced these forms of violence since the previous interview. We use the questions described above to create a binary variable that measures recent severe domestic violence in each wave. For Wave 1 the variable is coded

\footnotetext{
${ }^{4}$ This formula implicitly assumes that a respondent worked in all weeks in the month she reported to be working. Therefore, this imputed number of weeks worked is clearly an upper bound of the actual weeks worked. Compared with an alternative measure available in WES, the self-reported weeks worked in a calendar year, we found no evidence that one measure is superior than the other: Two measures are highly correlated, and a significant number of respondents actually have self-reported number of weeks that exceeds the upper bound. Furthermore, the selfreported annual weeks information is only available for the calendar year prior to an interview, that is, 1996-1998 with the first three waves of WES, but not for our latest analysis year, 1999. Therefore, we choose to use the measure imputed with percent of months worked due to its availability throughout the analysis periods.
} 
" 1 " if any of these forms of partner abuse occurred in the last 12 months, and for Wave 2 and Wave 3 if any of them occurred since the previous interview.

\section{Mental Health}

We used the WHO-CIDI-SF (Kessler, Andrews, Mroczek, Ustun, \& Wittchen, 1999) to measure whether or not the respondent meets criteria for major depression, social phobia, generalized anxiety disorder, drug dependence, and alcohol dependence. These disorders were included in the WES study because of the general prevalence or presumed links to employment effects. The diagnostic screening scales used are based on the National Comorbidity Study (NCS), the first nationally representative survey to administer a structured psychiatric interview (Kessler et al., 1994). The CIDI-SF scales correctly classify between 77 and $100 \%$ of CIDI cases, and between 94 and 99\% of CIDI noncases in the NCS. For the scales used in this study, overall classification accuracy ranges from $93 \%$ for depression to $99 \%$ for generalized anxiety disorder (Kessler et al., 1999). Posttraumatic stress disorder (PTSD) was measured using a modification of the UM-CIDI long form, which determines the past-year and lifetime prevalence of PTSD based on women's responses to the most upsetting traumatic event (not limited to domestic violence experiences). For this study, we use only the past-year specification. We create a binary categorical variable that is coded " 1 " if a respondent meet our diagnostic screening criteria for at least one of the six mental health disorders " 0 " if none was met during the 12 months prior to each wave. Because of differences in question design across waves, we did not measure social anxiety disorder at Wave 1 or generalized anxiety disorder at Wave 2.

\section{Physical Health}

We classify women's physical health problems based on two measures-whether she has serious physical limitations in functioning (scores in the bottom age-specific quartile) and whether her selfrated health is fair or poor, using subscales derived from the SF-36 (Ware, Snow, Kosinski, \& Gandek, 1993). We then define our physical health binary variable as 1 if a respondent has both health problems at a specific wave, 0 if either problem is not reported.

\section{Other Controlled Variables}

We also control for a number of other timevariant and time-invariant individual demographic characteristics and barriers to work as potential predictors of women's employment. Time-variant characteristics include a binary variable indicating whether the respondent is cohabiting with a husband or partner, the number of care-given children under age six in the household, and household size measured by the number of individuals living in the household. On the basis of work by Danziger et al. (2000) and using variable specification defined therein, binary variables are also included for another two barriers to employment reported at each wave-(1) transportation problems, indicated by the respondent's lack of either a car or driver's license; and (2) if the respondent cared for a child with a physical, learning, or mental health problem that limits their regular activities.

Because of the use of fixed effects approach (see next section), the effects of time-invariant variables cannot be estimated unless they interact with time.

We use two "year" binary categorical variables to capture general time-trends (with 1997 as the reference year), and we interact the years with four time-invariant variables that are likely to affect growth in work participation: (1) a race binary variable indicating if the respondent is African American; (2) a binary variable indicating if the respondent has less than high school education (lacks a high-school diploma or GED); (3) a binary variable indicating if the respondent had low work skills as of 1997 (indicated by the respondent's having experience with fewer than four of nine entry-level job skills in her previous or current jobs. The job skills include taking with customers, reading, writing, mathematical/computational skills, and/or has used computers or other electronic instruments in a job); and (4) the number of years the respondent received cash welfare since age 18 as of 1997 . The latter three are among the barriers to employment described in Danziger et al. (2000). The education barrier is by nature time-invariant for a majority of women in our universe. For work skill and years on welfare, we choose the baseline instead of the concurrent measure to reduce their endogeneity in predicting work.

Table I shows the descriptive statistics of all variables by year. The mean annual work hours is $971 \mathrm{hr}$ in 1997, $1309 \mathrm{hr}$ in 1998, and $1463 \mathrm{hr}$ in 1999 (the overall average for the 3 -year period is $1248 \mathrm{hr}$ ). Sixteen percent of the 1997 sample experienced severe abuse 
Table I. Descriptive Statistics of Variables

\begin{tabular}{|c|c|c|c|c|c|c|}
\hline \multirow[b]{2}{*}{ Variable names } & \multicolumn{2}{|c|}{1997 sample $(N=588)$} & \multicolumn{2}{|c|}{1998 sample $(N=589)$} & \multicolumn{2}{|c|}{1999 sample $(N=591)$} \\
\hline & Mean & $S D$ & Mean & $S D$ & Mean & $S D$ \\
\hline Domestic violence & 0.16 & 0.37 & 0.16 & 0.37 & 0.13 & 0.33 \\
\hline Mental health problems & 0.34 & 0.48 & 0.28 & 0.45 & 0.34 & 0.47 \\
\hline Physical health problems & 0.18 & 0.38 & 0.21 & 0.40 & 0.21 & 0.41 \\
\hline Number of children under age 6 & 1.03 & 0.95 & 0.93 & 0.93 & 0.84 & 0.94 \\
\hline Household size & 3.87 & 1.59 & 3.97 & 1.59 & 4.13 & 1.56 \\
\hline Transprortation problems & 0.44 & 0.50 & 0.34 & 0.47 & 0.30 & 0.46 \\
\hline Child with health problems & 0.22 & 0.42 & 0.17 & 0.38 & 0.14 & 0.34 \\
\hline Age $25-34$ in 1997 & 0.48 & 0.50 & 0.48 & 0.50 & 0.48 & 0.50 \\
\hline Low work skills & 0.20 & 0.40 & 0.20 & 0.40 & 0.20 & 0.40 \\
\hline Years on welfare since age 18 & 7.45 & 5.49 & 7.36 & 5.44 & 7.45 & 5.53 \\
\hline Workplace discrimination & 0.14 & 0.34 & 0.14 & 0.34 & 0.13 & 0.34 \\
\hline Little work experience & 0.14 & 0.35 & 0.14 & 0.35 & 0.14 & 0.35 \\
\hline Knew few workplace norms & 0.09 & 0.29 & 0.09 & 0.29 & 0.09 & 0.29 \\
\hline
\end{tabular}

in the year prior to Wave $1,16 \%$ of the 1998 sample experienced severe abuse between Wave 1 and Wave 2 , and $13 \%$ of the 1999 sample experienced it between Wave 2 and Wave 3. Of all 598 respondents in the analysis sample, $69.1 \%$ (413 respondents) never reported severe abuse, $2.3 \%$ (14 respondents) were persistently abused, and the other $28.6 \%$ (171 respondents) changed abuse status and reported severe abuse at one or two waves out of three.

In terms of mental health disorders, $34 \%$ of the sample of the sample had a past-year disorder in 1997, 28\% in 1998, and 34\% in 1999. Eighteen percent of the sample had a physical health problem in 1997, $21 \%$ in 1998 , and $21 \%$ in 1999.

\section{Analysis}

We conduct fixed-effects regressions to compare models that include and exclude presumed health and mental health mediators from the equation to explore the extent of the possibly mediated effects. Fixed-effect models take into account unobserved individual characteristics and give consistent estimators of the coefficients, provided that the unobserved traits and their effects do not change over time. The models contain individual-specific constant terms as explanatory variables, which absorb the observed or unobserved time-invariant characteristics of an individual. In addition to the complete model that includes all potential explanatory variables, we also estimate the equations excluding physical and mental health variables. Even if domestic violence does not have a direct effect on women's work, our mediation model predicts the coefficient of domestic violence to be significant in the absence of the physical and mental health variables.

A problem of simple OLS estimation, which has been more widely used in existing related research, is that the classic assumptions about the error term are likely to be violated because of the omission of unobserved individual characteristics that also affect the dependent variable. Examples of such characteristics include women's unobserved ability to work or her career aspiration. In such cases, the OLS estimators are at least inefficient (due to the serial correlation in the error term), and, even worse, they are inconsistent if the omitted characteristics are correlated with the controlled explanatory variables. For instance, a woman's career aspiration is a positive attribute that will increase her probability of employment. Meanwhile, men who are most threatened by their partners career aspirations, either because of personality, an ideology of male dominance, or an interaction of the two (Dutton, 1998), will be more likely to abuse their partners. Therefore, a woman's career aspirations may be positively associated with her partners' abusive behavior. This view is supported by studies documenting increased abuse when there is "status inconsistency" in couples, that is, when women have higher status jobs or make more money than their male partners (Hornung, McCullough, \& Sugimoto, 
1981; Hotaling \& Sugarman, 1986). Failure to control for this factor would cause the estimated coefficient of domestic violence to be upward biased (not in absolute terms), which means an underestimate of domestic violence's negative impact.

Under the fixed effects specification, the error term is uncorrelated with the controlled explanatory variables assuming that the unobserved individual characteristics do not change over time, and OLS estimators are now consistent. To avoid the cumbersome calculation resulting from the large number of binary variables, fixed effects estimation is usually accomplished by applying OLS to the equivalent meandeviated form of the underlying equations. As shown in the following equations, the annual work hours of woman $i$ in year $t$ is specified as a function of her experience of domestic violence during the same year and other characteristics:

$$
\begin{aligned}
\text { Annual Work Hours }_{i t}= & \beta \cdot{\text { Domestic } \text { Violence }_{i t}} \\
& +\gamma^{\prime} X_{i t}+\alpha_{i}+u_{i t} \\
& \Rightarrow\left(\text { Annual Work Hours }_{i t}\right. \\
& \left.-\overline{\text { Annual Work Hours }_{i}}\right) \\
= & \beta \cdot\left(\text { Domestic Violence }_{i t}\right. \\
& \left.-\overline{\text { Domestic Violence }_{i}}\right) \\
& +\gamma^{\prime}\left(X_{i t}-\overline{X_{i}}\right)+u_{i t}-\overline{u_{i}}
\end{aligned}
$$

where $i=1, \ldots, N, t=1997,1998$, and 1999; $X$ is a vector of controlled variables other than domestic violence; $\alpha_{i}$ is the individual-specific constant term that accounts for the time-invariant factors unique for individual $i$. As shown in Eq. (1), each variable is averaged over all assessed time points for a specific woman. This average value is then subtracted from the value at a specific time point for that woman. As a result, the time-invariant measured and unmeasured characteristics for a specific woman, such as race, drop out of the model. A fixed effects approach utilizes only the within variations (the over-time changes in the values of variables for an individual) but not the between variations (the differences in the levels of variables across individuals) in estimation. This is a cost it bears to eliminate the inconsistency issue caused by unobserved individual characteristics.

\section{RESULTS}

Table II presents the fixed-effects regression results of the work equation. All time-invariant vari- ables are absorbed by the individual-specific constant terms and drop out of the equation. Column 4 shows the full model controlling for both domestic violence and health variables. Domestic violence shows a significant impact on women's work activities. With the same mental and physical health status, the experience of domestic violence alone reduces a woman's annual work hours by $137 \mathrm{~h} .{ }^{5}$ The presence of physical health problems is significantly associated with less work; women who reported physical health problems work $112 \mathrm{hr}$ less than those who did not. The coefficient for mental health problems is statistically insignificant. $^{6}$

Columns 2 and 3 of Table II shows the fixedeffects regression results of the equations excluding health variables or domestic violence but not both. Omitting mental and physical health leads to a larger negative coefficient of domestic violence (a reduction of 149 work hours per year), which is a result of the positive association between domestic violence and health problems. We found little change from column 4 to column 3 , even though the omitted domestic violence variable is a significant predictor of annual work hours and one would expect to see larger (negative) coefficients of the health variables

\footnotetext{
${ }^{5}$ We also ran regressions with "percent of months worked in a year" as the employment measure. These alternative regression results generally agree with our findings from annual work hour regressions, although the estimated effects of domestic violence on work are considerably smaller in size when "percent of month worked" is used as the dependent variable. This is expected by the authors because the "percent of month worked" measure does not capture the varying work intensity within a working month, which our "annual work hours" measure does take into account. For example, among women who worked the same number of months in a year, some may work fewer hours per week than the others as a result of severe partner abuse. Such forms of impact would not be picked up by the "percent of months worked" regressions.

${ }^{6}$ For comparison purposes, we also estimated OLS models without the individual-specific constant terms. The OLS estimates of the coefficients of domestic violence remain negative but are insignificant and/or smaller in size. On the other hand, the OLS estimates of the coefficients of physical health remain negative and significant, and the sizes are more than twice as great as their fixed effects counterparts. Taken as a whole, these results suggest that the unobserved individual characteristics are positively correlated with domestic violence and women's employment, but negatively correlated with the presence of physical health problems. One possibility of such attributes is a woman's motivation to work or career aspiration. A woman's motivation to work may be threatening to a man who desires to control his partner, because of jealousy, insecurity, and/or an ideology of male dominance. On the other hand, a motivated woman may also be healthier because she tends to take better care of herself.
} 
Table II. Fixed-Effects Regressions Results Predicting Annual Work Hours

\begin{tabular}{|c|c|c|c|c|c|c|}
\hline & \multicolumn{2}{|c|}{$\begin{array}{c}\text { Domestic } \\
\text { violence only }\end{array}$} & \multicolumn{2}{|c|}{$\begin{array}{l}\text { Mental health and } \\
\text { physical health only }\end{array}$} & \multicolumn{2}{|c|}{$\begin{array}{l}\text { DV, mental health, } \\
\text { and physical health }\end{array}$} \\
\hline & Coefficient & $S E$ & Coefficient & $S E$ & Coefficient & $S E$ \\
\hline Domestic violence & $-148.59^{* *}$ & 58.92 & & & $-136.85^{* *}$ & 59.02 \\
\hline Mental health problems & & & -76.81 & 47.77 & -70.51 & 47.76 \\
\hline Physical health problems & & & $-120.52^{*}$ & 61.91 & $-112.39^{*}$ & 61.89 \\
\hline \multicolumn{7}{|l|}{ Time-variant demographics } \\
\hline Cohabiting with spouse or partner & 27.37 & 62.00 & 26.73 & 62.28 & 22.71 & 62.19 \\
\hline Number of children under age 6 & $-111.15^{* * *}$ & 41.81 & $-110.51^{* * *}$ & 41.82 & $-109.69^{* * *}$ & 41.74 \\
\hline Household size & -5.69 & 22.57 & -7.17 & 22.61 & -9.54 & 22.59 \\
\hline Transprortation problems & $-104.02^{*}$ & 59.77 & $-103.42^{*}$ & 59.81 & $-103.95^{*}$ & 59.70 \\
\hline Child with health problems & -29.35 & 57.73 & -31.41 & 57.77 & -29.89 & 57.67 \\
\hline \multicolumn{7}{|l|}{ Time-interactive terms of time-invariant variables } \\
\hline African American* Year 1998 & -9.67 & 74.29 & -18.28 & 74.24 & -9.96 & 74.19 \\
\hline Less than high school education* Year 1998 & -100.19 & 82.80 & -93.47 & 82.88 & -92.59 & 82.73 \\
\hline Low work skills* Year 1998 & $269.97^{* * *}$ & 95.31 & $261.92^{* * *}$ & 95.38 & $263.73^{* * *}$ & 95.20 \\
\hline Years on welfare since age $18^{*}$ Year 1998 & -6.16 & 6.85 & -6.46 & 6.85 & -6.08 & 6.84 \\
\hline African American* Year 1999 & 69.79 & 74.15 & 61.83 & 74.15 & 67.24 & 74.04 \\
\hline Less than high school education* Year 1999 & -21.83 & 82.64 & -19.93 & 82.70 & -16.88 & 82.56 \\
\hline Low work skills* Year 1999 & 140.01 & 94.72 & 138.08 & 94.79 & 136.34 & 94.61 \\
\hline Years on welfare since age 18* Year 1999 & $-17.75^{* * *}$ & 6.79 & $-17.33^{* *}$ & 6.80 & $-17.36^{* *}$ & 6.79 \\
\hline \multicolumn{7}{|l|}{ Time trends } \\
\hline Year 1998 dummy & $345.66^{* * *}$ & 74.26 & $351.37^{* * *}$ & 74.36 & $344.35^{* * *}$ & 74.28 \\
\hline Year 1999 dummy & $526.69^{* * *}$ & 75.46 & $536.86^{* * *}$ & 75.49 & $530.26^{* * *}$ & 75.40 \\
\hline Number of observation & 1768 & & 1768 & & 1768 & \\
\hline Number of groups & 598 & & 598 & & 598 & \\
\hline$F$ statistics on model $(17,1153)$ & $14.47^{* * *}$ & & $13.64^{* * *}$ & & $13.23^{* * *}$ & \\
\hline Within $R^{2}$ & 0.1671 & & 0.1674 & & 0.1713 & \\
\hline Overall $R^{2}$ & 0.0797 & & 0.0926 & & 0.0955 & \\
\hline$F$ statistics on fixed effects $(597,1153)$ & $3.05^{* * *}$ & & $2.97^{* * *}$ & & $2.98^{* * *}$ & \\
\hline
\end{tabular}

Note. A respondent must have at least two valid observations to be included in the analysis sample.

${ }^{*} p<.1{ }^{* *} p<.05 ;{ }^{* * *} p<.01$.

in the absence of domestic violence because they are positively associated. Indeed, the coefficients of both mental and physical health problems in column 3 are larger in size than in the full model, but the change is small and mental health's effect remains insignificant.

The other factors that significantly affect women's work include the number of children under age 6 , having transportation problems, time trends, and the interaction terms between year and selected time-invariant characteristics. Having an additional care-given child under age 6 reduces a woman's work by $110 \mathrm{hr}$ per year. Having transportation problems (lack of a car or a driver's license) reduces work by 104 per year. An average woman work $344 \mathrm{hr}$ more in 1998 and $530 \mathrm{hr}$ more in 1999 compared to her work in the base year 1997; these large year effects are attributable to a combination of welfare reform and the booming economy. An additional year on welfare re- duces the growth in women's work hours from 1997 to 1999 by $17 \mathrm{hr}$. Women who had low work skills as of 1997 have a significantly larger increase in work hours from 1997 to 1998 (though such tendency did not last through 1999). Although this result may be somewhat counter-intuitive at the first look, we think it is plausible because it is likely that higher skilled women were already working significant amount of time in 1997, and therefore have a more limited range to improve on the hours worked in the later years as the work-promoting welfare reform proceeded.

The fixed effect results suggest that domestic violence does have significant impact on women's employment even when women's health status is controlled for. On the other hand, the larger estimated effect of domestic violence on work in the absence of physical and mental health variables suggests that domestic violence may also affect women's work by negatively influencing their health. 


\section{DISCUSSION}

Our results support the contention that domestic violence is associated with diminished work hours for women. The size of the effect of domestic violence on women's employment is worth noting. A reduction of $137 \mathrm{hr}$ is more than $10 \%$ of the annual work hours of an average woman in our 3-year sample (1248 hr). Our estimate of the growth in women's work hours was 344 for the first to second wave, and 186 (530344 ) for the second to third wave. These gains can probably be attributed to a booming economy as well as the changes in welfare laws. The effects of domestic violence essentially offset almost $40 \%$ of that gain (137/344) for women who experienced violence between the first and second wave, and almost $75 \%$ (137/186) of that gain between the second and third wave. In "real life" terms, domestic violence wipes out a substantial portion of the employment gains women might otherwise have experienced.

Our finding that domestic violence is associated with a reduction in employment is consistent with feminist theory. Although we did not measure and cannot test the individual motivation of the men who abused their partners, we do demonstrate that domestic violence is associated with the structural results predicted by feminist theory. Given that our analysis controls for unmeasured individual characteristics of the women as well as relevant demographic characteristics and health and mental conditions, our results are also consistent with feminist theory in that the association between domestic violence and employment is not explained by individual characteristics of the women who experience abuse by their partners.

The link between diminished work hours and domestic violence raises concern about the economic well-being of domestic violence victims within the welfare system. Other analyses of WES data demonstrated that lower work hours were associated with lower income (Danziger, Heflin, Corcoran, Oltmans, \& Wang, 2002). We also found domestic violence was associated with various forms of material deprivation (e.g., food insufficiency, lack of stable housing, and utility shut-offs) as well as increased welfare dependence, and decreased work reliance (Tolman et al., under review). Women experiencing domestic violence are also more likely to experience subjective hardship, that is, they are more concerned about their current and future ability to manage on the amount of family income they are or expect to receive. It is likely that decreased work is one reason for the increased hardship that domestic violence victims experience. As economic activity is decreased, they will be more likely to continue to need supplemental income. Diminished earnings could also make women more vulnerable to staying in an abusive relationship, if their partner provides economic or other types of support (e.g., child care).

Given our findings here of decreased work effort, and other evidence of greater hardship and increased welfare reliance related to domestic violence, continued efforts are needed within the welfare system to address the needs of domestic violence victims. The Family Violence Option, adopted by nearly all states (Raphael \& Haennicke, 1999) provides for a number of remedies that states may provide for welfare recipients to address domestic violence. Among the strategies adopted are training for welfare caseworkers, screening, assessment, and safety planning by welfare caseworkers, referrals to domestic violence specialists, temporary waivers from work requirements, extension of time limits, and good cause exemptions from child paternity establishment (Burt, Zweig, \& Schlichter, 2000; Tolman \& Raphael, 2000).

Because many of the WES respondents had left the welfare rolls by the third wave, implications for our data do not rest within the welfare system alone. Our study also provides support for efforts to address domestic violence in the workplace. Diminished work hours may be due to absences from work, as well as job loss. Several studies have linked job loss to domestic violence (Moore \& Selkowe, 1999; Sable, Libbus, Huneke, \& Anger, 1999). A number of remedies have been suggested to address domestic violence issues in the workplace. Emergency leave may be necessary when women need to protect their safety, either by seeking shelter, avoiding contact with their partners, or to pursue legal options such as orders for protection. In jobs where such leaves are unavailable, taking time off to protect herself or her family can result in lost wages or job loss. Women who lose their jobs because of domestic violence are not eligible for unemployment compensation in most states (NOW Legal Defense and Education Fund, 2003). Legislation to make such benefits available could provide an important safety net for women who have left the welfare system for employment and prevent others from entering the rolls. Finally, victims need protection from employment and insurance discrimination based on their status as domestic violence victims. Fear of job loss or other discrimination may keep some women from disclosing their status to employers or others, diminishing their options 
for safety in the workplace. These provisions (i.e., emergency leave, unemployment compensation, and protection from employment discrimination based on victim status, along with tax credits for employers who implement these remedies) have been proposed in recent legislation, the Victims' Economic Security and Safety Act (VESSA; H.R. 2670 and S. 1249; NOW Legal Defense and Education Fund, 2001). Clearly, this type of legislation moves beyond the provisions of the FVO, and expands protections for domestic violence victims into employment settings.

One limitation of our study is that we have not addressed the causal direction of the domestic violence/employment association. Although we predicted that domestic violence would act as a barrier to employment, it is possible, and not inconsistent with our theory, that employment reduces domestic violence. From a feminist perspective, employment would empower women to be economically autonomous and to have the power to leave abusive relationships they would otherwise be dependent upon. However, given that past studies have not found a consistent association with domestic violence and employment, we first wanted to demonstrate such an association. The direction of the domestic violence/employment effect, however, has recently received some attention in the literature.

Several recent studies evaluating welfare-towork programs have linked domestic violence and employment, but have reversed the presumed causal direction of the effect. (Hamilton, 2002; Knox, Miller, \& Gennetian, 2000). Research on the effects of employment on domestic violence reveals mixed and inconsistent findings. Some studies have found no effect (Fox, Benson, DeMaris, \& Wyk, 2002; Tauchen \& Witte, 1995), whereas others have found that women's employment increases incidents of domestic violence. Macmillan and Gartner (1999) found an increase in domestic violence only in the case that the woman's partner was unemployed; Rodriguez, Lasch, Chandra, and Lee (2001) found an increase in domestic abuse only in cases where the woman was receiving welfare. Still others contend that women's employment is linked to a decrease in domestic abuse (Farmer \& Tiefenthaler, 1997). Using data collected from two large, experimental welfare programs that encouraged labor force participation among a sample of low-income welfare-reliant mothers, Gibson, Magnuson, Gennetian, Duncan, and England (2002) found that women's employment reduced certain types of domestic abuse. They suggest this reduction in abuse is due to increased self-esteem, expanded social networks and support, or simply spending more time away from abusive partners or ex-partners. In her analysis of a pilot welfare program in Minnesota that increased participants' employment and income, Gennetian (2003) found decreased reports of domestic abuse in urban counties and increased reports of abuse in rural counties. She attributed this discrepancy between effects on participants in rural and urban counties to differences in access to social services, differences in the characteristics of the welfare population, and differences in the effects of the program on economic well-being.

At this stage, we do not find the directionality of the effect the most important question to consider. It is likely that effects exist in both directions and future research should address the issue of directionality. Regardless of whether employment reduces the risk of domestic violence, or domestic violence reduces the probability, quantity, or quality of employment, women must be supported in their efforts to go to work safely. Within the welfare system, temporary waivers and exemptions from work requirements may be necessary for women who cannot go to work safely, or who are sabotaged in their efforts to work. Efforts to promote women's eventual safe entry into the work place would still be necessary to promote their economic security.

Although we argue that the investigation of the potential work impact of domestic violence is particularly salient for women receiving welfare, it is important to note that the results of this study may not be generalizable to other populations. Because the women were selected specifically because they were unmarried women with children receiving some form of financial assistance from the state, the ways in which domestic violence influences their work trajectories may differ from those in different economic circumstances and with varying family configurations.

Our results demonstrate employment effects of domestic violence beyond the partially mediating effects of physical and mental health. However, subsequent research is needed to more fully understand the impact of various health and mental issues resulting from violence on employment. Our health variable was a broad measure, based primarily on self-report and did not allow us to assess the impact of specific health conditions on the employment trajectories of women in the study. In addition, we included numerous mental health disorders into a 
single variable. Subsequent research should explore specific disorders and conditions and their impact on employment. Some disorders may not have an immediate impact on employment, but may over time diminish job success. On the other hand, cessation of violence may result in relatively rapid dimishment of various disorders, but some chronic conditions may remain even when violence ends. Ultimately, the mediating effects of these adverse outcomes of violence on employment is likely to be a nuanced and complex picture. Analyses of longitudinal data, with adequate measures of disorders over time will be needed to further understand the role these adverse sequelae of intimate violence has on employment over time.

\section{ACKNOWLEDGMENTS}

This research was supported in part by grants from the U.S. Department of Health and Human Services. Office of the Assistant Secretary for Planning and Evaluation, the Joyce Foundation, the Charles Stewart Mott Foundation, the John D. and Catherine T. MacArthur Foundation, the National Institute of Mental Health (R24-MH51363), and the Office of the Vice President for Research at the University of Michigan. The authors thank survey manager Bruce Medbery and the interview staff. Kyong Yi and Candace Cadena provided valuable assistance on the manuscript. We also thank Deb Bybee, Cris Sullivan, and two anonymous reviewers and the journal editors for their comments on previous previous draft.

\section{REFERENCES}

Allard, M. A., Albelda, R., Colten, M. E., \& Cosenza, C. (1997). In harm's way? Domestic violence, AFDC receipt, and welfare reform in Massachusetts. Boston: University of Massachusetts, McCormack Institute and Center for Survey Research.

Barusch, A., Taylor, M. J., Abu-Bader, S. H., \& Derr, M. (1999). Understanding families with multiple barriers to selfsufficiency. Salt Lake City: University of Utah, Social Research Institute.

Bograd, M. (1988). Feminist perspectives on wife abuse: An introduction. In M. Bograd \& K. Yllo (Eds.), Feminist perspectives on Wife Abuse. Beverly Hills: Sage.

Browne, A., Salomon, A., \& Bassuk, S. S. (1999). The impact of recent partner violence on poor women's capacity to maintain work. Violence Against Women, 5(4), 393.

Burt, M. R., Zweig, J. M., \& Schlichter, K. (2000). Strategies for addressing the needs of domestic violence victims within the TANF program: The experience of seven counties (Final Report). Washington, DC: Urban Institute.

Campbell, J., Jones, A. S., Dienemann, J., Kub, J., Schollenberger, J., \& O'Campo, P., et al. (2002). Intimate partner violence and physical health consequences. Archives of Internal Medicine, 162(10), 1157-1163.
Campbell, J. C. (2002). Health consequences of intimate partner violence. Lancet, 359(9314), 1331-1336.

Campbell, J. C., \& Lewandowski, L. A. (1997). Mental and physical health effects of intimate partner violence on women and children. Psychiatric Clinics of North America, 20(2), 353.

Coker, A. L., Davis, K. E., Arias, I., Desai, S., Sanderson, M., \& Brandt, H. M., et al. (2002). Physical and mental health effects of intimate partner violence for men and women. American Journal of Preventive Medicine, 23(4), 260-268.

Danziger, S. H., Heflin, C. M., Corcoran, M. E., Oltmans, E., \& Wang, H. C. (2002). Does it pay to move from welfare to work? Journal of Policy Analysis and Management, 21(4), 671-692.

Danziger, S. K., Corcoran, M., Danziger, S. H., Heflin, C., Kalil, A., Levine, J., et al. (2000). Barriers to the employment of welfare recipients. In R. D. Cherry \& W. M. Rodgers (Eds.), Prosperity for all?: The economic boom and African Americans (pp. 239-277). New York: Russell Sage.

Dobash, R. P., \& Dobash, R. E. (1979). Violence against wives: A case against the patriarchy. New York: Free Press.

Dutton, D. G. (1998). The abusive personality: Violence and control in intimate relationships. New York: Guilford Press.

Farmer, A., \& Tiefenthaler, J. (1997). An economic analysis of domestic violence. Review of Social Economy, 55(3), 337358.

Fox, G. L., Benson, M. L., DeMaris, A. A., \& Wyk, J. V. (2002). Economic distress and intimate violence: Testing family stress and resources theories. Journal of Marriage and Family, 64(3), 793.

Gelles, R. (1993). Through a sociological lens: Social structure and family violence. In R. Gelles \& D. Loseke (Eds.), Current controversies on family violence (pp. 31-46). London: Sage.

Gennetian, L. A. (2003). Welfare policies and domestic abuse among single mothers: Experimental evidence from Minnesota. Violence Against Women, 9(10), 1171.

Gibson, C., Magnuson, K., Gennetian, L., Duncan, G., \& England, P. (2002). "Does employment protect women from domestic violence?" Paper. Association for Public Policy Analysis and Management Annual Meeting. Dallas, TX, November 2002.

Golding, J. M. (1999). Intimate partner violence as a risk factor for mental disorders: A meta-analysis. Journal of Family Violence, 14(2), 99-132.

Goodwin, S. N., Meisel, J., Chandler, D., Jordan, P., \& Kushner, S. (2000). The CalWORKs project: The prevalence of mental health, alcohol and other drug, and domestic violence issues among CalWORKs participants in Kern and Stanislaus Counties. Sacramento: California Institute for Mental Health.

Hamilton, G. (2002). Moving people from welfare to work: Lessons from the national evaluation of welfare-to work strategies. Retrieved October 24, 2002, from http://www.mdrc.org/ Reports2002/NEWWS_Synthesis/NEWWS_Synthesis.pdf

Hornung, C. A., McCullough, B. C., \& Sugimoto, T. (1981). Status relationships in marriage-Risk factors in spouse abuse. Journal of Marriage and the Family, 43(3), 675-692.

Hotaling, G. T., \& Sugarman, D. B. (1986). An analysis of risk markers in husband to wife violence: The current state of knowledge. Violence and Victims, 1, 101-124.

Kessler, R. C., Andrews, G., Mroczek, D., Ustun, B., \& Wittchen, H.-U. (1998). The World Health Organization Composite International Diagnostic Interview Short-Form (CIDI-SF). International Journal of Methods in Psychiatric Research, 7(4), $171-185$.

Kessler, R. C., McGonagle, K. A., Zhao, S. Y., Nelson, C. B., Hughes, M., Eshleman, S., et al. (1994). Lifetime and 12month prevalence of DSM-III-R psychiatric disorders in the United States: Results from the National Comorbidity Survey. Archives of General Psychiatry, 51(1), 8-19.

Knox, V., Miller, C., \& Gennetian, L. (2000). Reforming welfare and rewarding work: A summary of the full report on 
the Minnesota Family Investment Program. New York: Manpower Demonstration Research Corporation.

Lloyd, S. (1997). The effects of domestic violence on women's employment. Law and Policy, 19(2), 139-167.

Lloyd, S., \& Taluc, N. (1999). The effects of male violence on female employment. Violence Against Women, 5(4), 370-392.

MacMillan, R., \& Gartner, R. (1999). When she brings home the bacon: Labor-force participation and the risk of spousal violence against women. Journal of Marriage and the Family, 61(4), 947.

Moore, T., \& Selkowe, V. (1999). Domestic violence victims in transition from welfare to work: Barriers to self-sufficiency and the W-2 response. Milwaukee: Institute for Wisconsin's Future.

NOW Legal Defense and Education Fund. (2001). Victims' Economic Security and Safety Act (VESSA) summary. Retrieved October 24, 2002, from http://www.nowldef.org/html/issues/ vio/VESSA_Summary080701.pdf

NOW Legal Defense and Education Fund. (2003). Security and Financial Empowerment Act "SAFE" factsheet. Retrieved January 27, 2004, from http://www.nowldef.org/html/issues/ vio/SAFEFactSheet.pdf

Pearson, J., Thoennes, N., \& Griswold, E. A. (1999). New approaches to self-sufficiency and safety in public assistance and child support agencies: Preliminary findings from three demonstration projects: (Available from the Center for Policy Research, 1570 Emerson Street, Denver, CO 80218).

Porcerelli, J. H., Cogan, R., West, P. P., Rose, E. A., Lambrecht, D., \& Wilson, K. E., et al. (2003). Violent victimization of women and men: Physical and psychiatric symptoms. Journal of the American Board of Family Practice, 16(1), 32-39.

Raphael, J. (1995). Domestic violence: Telling the untold welfareto-work story: (Available from Center for Impact Research, 915 N. Wolcott, Chicago, IL 60222).

Raphael, J. (1996). Prisoners of abuse: Domestic violence and welfare receipt: (Available from Center for Impact Research, 915 N. Wolcott, Chicago, IL 60222).

Raphael, J. (2000). Saving Bernice: Battered Women, welfare and poverty. Boston, M. A.: Northeastern University Press.

Raphael, J., \& Haennicke, S. (1998). The family violence option: An early assessment. A Taylor Institute report submitted to the Federal Department of Health and Human Services, Washington, DC.
Raphael, J., \& Haennicke, S. (1999). Keeping battered women safe through the welfare-to-work journey: How are we doing? A report on the implementation of policies for battered women in state temporary assistance for needy families (TANF) programs: (Available from Center for Impact Research, $915 \mathrm{~N}$. Wolcott, Chicago, IL 60222).

Riger, S., \& Krieglstein, M. (2000). The impact of welfare reform on men's violence against women. American Journal of Community Psychology, 28, 631-647.

Rodriguez, E., Lasch, K. E., Chandra, P., \& Lee, J. (2001). Family violence, employment status, welfare benefits, and alcohol drinking in the United States: what is the relation? Journal of Epidemiology and Community Health, 55(3), 172178.

Sable, M. R., Libbus, M. K., Huneke, D., \& Anger, K. (1999). Domestic violence among AFDC recipients: Implications for welfare-to-work programs. Affilia, 14(2), 199.

Straus, M. A. (1979). Measuring intra-family conflict and violence: Conflict Tactics (CT) Scales. Journal of Marriage and the Family, 41(1), 75-88.

Sutherland, C. A., Bybee, D. I., \& Sullivan, C. M. (2002). Beyond bruises and broken bones: The joint effects of stress and injuries on battered women's health. American Journal of Community Psychology, 30(5), 609-636.

Sutherland, C. A., Sullivan, C. M., \& Bybee, D. I. (2001). Effects of intimate partner violence versus poverty oil women's health. Violence Against Women, 7(10), 1122-1143.

Tauchen, H., \& Witte, A. D. (1995). The dynamics of domestic violence. The American Economic Review, 85(2), 414.

Tolman, R. M., \& Raphael, J. (2000). A review of research on welfare and domestic violence. Journal of Social Issues, 56(4), 655-681.

Tolman, R. M., \& Rosen, D. (2001). Domestic violence in the lives of women receiving welfare: Mental health, substance dependence, and economic well-being. Violence Against Women, $7(2), 141-158$.

Ware, J. E., Snow, K. K., Kosinski, M., \& Gandek, B. (1993). SF-36 health survey: Manual and interpretation guide. Boston: The Health Institute.

Yllo, K. A. (1993). Through a feminist lens: Gender, power, and violence. In R. J. Gelles \& D. R. Loseke (Eds.), Current controversies on family violence. Newbury Park, CA: Sage. 